\title{
Chances and Barriers of Online Problem- Based Learning (ePBL) for Advanced Training in the Healthcare Sector
}

\author{
Hilke MANSHOLT ${ }^{\mathrm{a}, 1}$, Nina-Alexandra GÖTZ ${ }^{\mathrm{a}}$ and Birgit BABITSCH ${ }^{\mathrm{a}}$ \\ a Osnabrück University, Department New Public Health, Osnabrück, Germany
}

\begin{abstract}
An online advanced training for professionals within the healthcare sector was developed including a problem statement to be solved following the steps of problem-based learning (PBL).The findings show that it is feasible to transfer PBL electronically (ePBL) where participants favoured the flexibility and time independency of ePBL. However, the evaluation revealed issues with the learning platform, insufficient technical conditions in the hospitals and a lack of personal exchange. Thus, ePBL offers advantages especially for advanced training in the healthcare sector but requires adaptations and the necessary technical prerequisites.
\end{abstract}

Keywords. online problem-based learning, advanced training, interactive learning environment, healthcare staff, ePBL

\section{Introduction}

In the research project „Gestaltungskompetenz as an Innovator for High Reliability Organizations in the Healthcare System" (GIO) an interactive learning environment was generated, serving as an advanced training for professionals within the healthcare sector. In this context, two modules ("Creating patient safety highly reliable"; and "Cultural diversity and communication") were developed and tested. Besides a theoretical knowledge transfer, participants had to solve an authentic problem statement following the concept of problem-based learning (PBL) [1]. PBL was chosen due to its learning success (e. g. in critical thinking) and its increased usage as a teaching method, especially in medical and healthcare education. The method is characterized by the so-called 7-step approach including 1. clarifying terms and concepts, 2. formulation of the problem statement, 3. idea brainstorming, 4. categorizing and structuring ideas, 5. formulation of learning objectives, 6 . resolution through self-study, and 7. conclusion by peer evaluation [2]. Further, PBL is usually performed synchronous and in presence [3]. Since to our knowledge, it is the first attempt in which all steps of PBL were realized completely online in an advanced training the first test phase aimed to determine chances and barriers of electronic PBL (ePBL), in the healthcare sector.

\footnotetext{
${ }^{1}$ Corresponding Author, Hilke Mansholt, E-mail: hilke.mansholt@uos.de
} 


\section{Methods}

To create an online environment for advanced training, use was made of the learning platform Moodle. The modules were split into two sections, starting with a theoretical knowledge transfer Afterwards, participants were confronted with a real-life problem statement based on the topic of the course which had to be solved as a group, following the steps of PBL. Each step was translated online using various interactive features provided by Moodle (e.g. Etherpad, journal entries, ballots, mind-maps, forum, chat, literature). The testing was conducted from November 2019 till February 2020 with a cooperating hospital group and their staff $(n=12)$ from all over Germany.

\section{Results}

The participants were able to finish all tasks of the module and in total 6 participants completed the course and the post-evaluation survey ("Creating patient safety high reliable $n=4$; "cultural diversity and communication $n=2$ ). After the training, the participants stated that they had gained new theoretical knowledge that was useful to them in their daily work. Furthermore, participants favored the flexibility and time independency the online advanced training offers, which was easy to combine with their occupational duties. During the course, technical challenges emerged, resulting from specific conditions in hospitals with limited access to internet or missing soft- and hardware as well as issues related to Moodle such as difficulties in navigation. Further, participants would have liked more personal exchange.

\section{Discussion and Conclusions}

In general, the realization ePBL is possible and revealed advantages as well as barriers. The majority of the reported issues were technical and related to the hospitals or Moodle itself, rather than with ePBL. Further, the exchange between participants was limited due to the asynchronous approach. Thus, future ePBL in online advanced trainings should target a mix of synchronous and asynchronous components. Nevertheless, advanced trainings in hospitals are often performed synchronous and in presence implying the absence of staff in shifts. ePBL however is not place bound but very self-determined with regard to time-management and thus easy to adjust or integrate into the work of healthcare staff offering authentic and effective trainings.

The translation of PBL online is possible and offers great benefits for advanced trainings in the healthcare sector. Still, adaptations of the learning platform, technical conditions in the hospitals and the translation of the PBL steps online need to be made.

\section{References}

[1] Reusser K, Problemorientiertes Lernen. Tiefenstruktur, Gestaltungsformen, Wirkung. Beitr Lehrerbild. 2005;23:159-182.

[2] Wang D, Samaka M, Miao Y. A model-driven PBL application to support the authoring, delivery, and execution of PBL processes. RPTEL. 2016;11:6.

[3] Fischer R. Problemorientiertes Lernen in Theorie und Praxis. Leitfaden für Gesundheitsfachberufe. Kohlhammer Verlag, Stuttgart, 2004. 